DOI 10.37882/2500-3682.2020.05.05

\title{
ФОРМИРОВАНИЕ ПОЗИТИВНОГО САМООТНОШЕНИЯ СТУДЕНТОВ-ПСИХОЛОГОВ ПОСРЕДСТВОМ ТРЕНИНГА РАЗВИТИЯ ФЛЕКСИБИЛЬНОСТИ
}

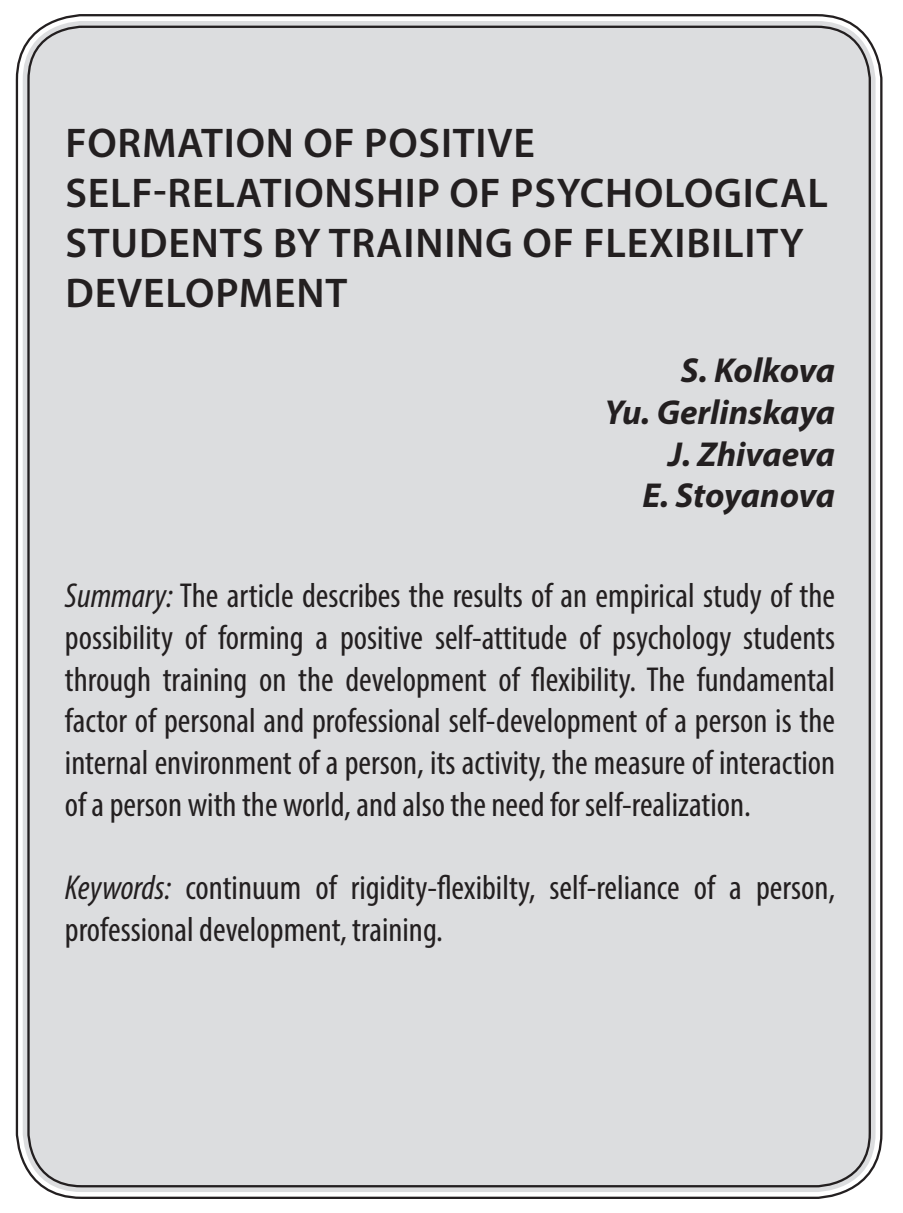

$\mathrm{B}$ современном обществе происходят перемены во всех сферах жизнедеятельности. Эти перемены характеризуются обострением противоречий между потребностью утвердить себя в окружающем мире, реализовать себя в обществе и необходимостью адаптации к складывающимся жизненным реалиям. Проблемы профессиональной подготовки будущих специалистов приобретают особую значимость.

По мнению Клочко В.Е. «...основополагающим фактором личностного и профессионального саморазвития человека, является внутренняя среда личности, ее активность, мера взаимодействия человека с окружающим миром, а также потребность в самореализации. Неготовность, затрудненность в изменении намеченной субъектом программы деятельности в условиях, требующих ее перестройки согласно новым ситуационным требованиям обозначается понятием ригидность (лат. rigidus - жесткий, твердый). Чем выше ригидность, тем
Колкова Светлана Михайловна

К.nсх.н., практический психолог, дочент, ФГБОУ ВО «Сибирский федеральный университет» (2. Красноярск) kolkova67@mail.ru

Герлинская Юлия Викторовна

ФГАОУ ВО «Сибирский федеральный университет»; педагог-психолог, СШ №150 имени Героя Советского Союза

В.С. Молокова

Живаева Юлия Валерьяновна

К.nсх.н., дочент, ФГБОУ ВО «КрасГМУ

им. проф. В.Ф. Войно-Ясенецкого» Минздрава России (2. Красноярск) yul-zhivaeva@yandex.ru

Стоянова Екатерина Иннокентьевна

К.nсх.н., дочент, ФГБОУ ВО «КрасГМУ

им. проф. В.Ф. Войно-Ясенецкого» Минздрава России

(2. Красноярск)

katya-chernova@yandex.ru

Аннотация: В статье представлено описание результатов эмпирического исследования возможности формирования позитивного самоотношения студентов-психологов посредством тренинга развития флексибильности. Основополагающим фактором личностного и профессионального саморазвития человека, является внутренняя среда личности, ее активность, мера взаимодействия человека с окружающим миром, а также потребность в самореализации.

Ключевые слова: континиум ригидности-флексибильности, самоотношение человека, профессиональное становлению, тренинг.

сильнее блокируются каналы выхода во внешнюю среду, тем сильнее игнорируются возможности самореализации, которые открываются во взаимодействии человека со средой, тем вероятнее появление поведенческих и других стереотипов в неадекватных для них условиях. Противоположное ригидности свойство обозначается термином «флексибильность». Флексибильность - это способность индивидуума изменить свою психическую установку или легко приспособиться к изменившейся ситуации. Под личностной флексибильностью понимается носящая положительную окраску способность индивида легко отказываться от несоответствующих ситуации или задаче средств деятельности, приемов мышления, способов поведения и вырабатывать или принимать новые, оригинальные подходы к разрешению проблемной ситуации при неизменных целях и идейно-нравственных основаниях деятельности»[4].

По определению Г.В. Залевского «...ригидность явля- 
ется тем общесистемным свойством, которое может не только блокировать выход человека за пределы устоявшихся поведенческих схем, но и за пределы жизненных обстоятельств, деятельность в которых предполагает трансформацию фиксированных форм поведения. Она тем самым может блокировать и сам вывод в сознание определенных жизненных обстоятельств, которые связаны с неудачами реализации в них стереотипов, сложившихся в других обстоятельствах. Ригидность также способна блокировать в сознании и те обстоятельства, которые связаны с открывающимися возможностями выхода за пределы требований ситуации - туда, где наиболее явно заявляет о себе мотивация достижения» [2].

Актуальность исследования проблемы континиума ригидности -флексибильности вытекает из все чаще встречающихся в литературе указаний на то, что внутренняя среда личности, а в нашем случае это особенности показателей самоотношения человека, делает систему либо открытой, либо частично закрытой, изолированной, остающуюся как бы застывшей. (Галажинский Э.В., 1996; Залевский Г.В., 1992; Клочко Ю.В., 2002, Логинова И.О., 2010, Лукьянов О.В.,1999.)

В диссертационном исследовании Ю.Е. Клочко [3] рассматривалась проблема ригидности как компонента в структуре готовности человека к изменению внутренней среды личности - самоотношения. Ригидность понималась как «...один из факторов, определяющих то, насколько система готова к самоизменениям, т.е. какова способность человека, понимаемого в качестве открытой системы, изменять свой образ жизни и свой образ мира в процессе жизни. При этом и сама выступает как непрерывный процесс разрешения постоянно воспроизводимого противоречия между образом жизни и образом мира человека». В диссертационном исследования представлены результаты математической статистики подтверждающие взаимосвязь характеристик самоотношения и показателей ригидности личности.

По мнению С.М. Колковой « ...в юности активно идет процесс социализации, и молодой человек осваивает новые социальные роли. Если в детстве роли для ребенка определяли взрослые, то с наступлением юности возникает задача самостоятельного выбора и интерпретации ролевого поведения. Формирование самоотношения как аффективного компонента самосознания осуществляется на двух уровнях самопознания. На первом уровне эмоционально-ценностное самоотношение возникает как результат соотнесения человеком себя с другими людьми. В этом случае при познании себя человек преимущественно опирается на внешние моменты. Ведущими формами самопознания в рамках сравнения «Я-другой» являются самовосприятие и самонаблюдение. На втором, более зрелом уровне самопознания, формирование самоотношения осуществляется в рам- ках сравнения «Я-Я» посредством внутреннего диалога. Ведущими формами такого самопознания являются самоанализ и самоосмысление» [5].

Одной из наиболее известных и цитируемых концепций, посвященных самоотношению личности, является теория С.Р. Пантелеева. В ней самоотношение определяется через соотнесение с иерархической системой мотивов, предложенной С.Р. Пантелеев предполагает, что ядром самоотношения в раннем юношеском возрасте является аутосимпатия, которая по мере пополнения социального опыта замещается на самоуважение.

Фундаментальным условием профессионального развития специалистов, работающих с людьми, а в нашем исследовании выборка представлена студентами, обучающимися по специальности «Клиническая психология» является осознание этими специалистами необходимости изменения, преобразования своего внутреннего мира и поиска новых возможностей самоосуществления в профессиональном труде, то есть повышение уровня профессионального самосознания. На основании описанного выше мы организовали и реализовали эмпирическое исследование на тему: «Формирование позитивного самоотношения студентов-психологов посредством тренинга развития флексибильности».

Выборка исследования представлена студентами, обучающимися по специальности «Клиническая психология» ФГБОУ ВО КрасГМУ им. проф. В.Ф. Войно-Ясенецкого Минздрава России в количестве 20 человек и студентами обучающимися по специальности «Психология» ФГБОУ ВО «Сибирский федеральный университет» в количестве 20 человек. Средний возраст исследуемых 19-20 лет

В качестве диагностического инструментария нами были использованы: Опросник самоотношения направлен на выявление уровня самоотношения испытуемого к самому себе. Разработан В.В. Столиным и С.Р. Пантилеевым в 1985 году. С целью исследования ригидности, в качестве диагностического инструментария мы использовали тестовую методику - Томский опросник ригидности (ТОР) Г.В. Залевского.

При сопоставлении результатов исследования по обеим методикам, нами было выявлено следующее соотношение: испытуемым, у которых был выявлен высокий и очень высокий уровень ригидности, характерно негативное самоотношение, в то время как испытуемым с низким и умеренным уровнем ригидности (проявление флексибильности) в большей характерно позитивное самоотношение.

Данные исследования свидетельствуют о примерной равноценности состава групп. Для выявления равноценности состава групп мы использовали t-критерий 
Стьюдента (для несвязанных выборок). По методике ТОР полученное значение tэмп. (от 1,55-до 1,87) по всем шкалам находится в зоне не значимости (t кр. $=1,97 ; \mathrm{p}<0,05)$, что говорит о статистической не существенности различий между выборками. По методике «Опросник самоотношения» так же полученное значение тэмп. (от 1,68 до $1,88)$ по всем шкалам находится в зоне не значимости $(t$ кр.=1,97; р < 0,05), что подтверждает статистическую не существенность различий между выборками.

Исходя из показателей первичной диагностики, для определения эффективности программы тренинга экспериментальной группой была определена 1-я группа (специальность «Клиническая психология»), тогда как 2-я (специальность «Психология») была определена как контрольная группа .

Основываясь на работы Э.В. Галажинского «Ригидность как общесистемное свойство человека и самореализация личности», Г.В. Залевского «Теория фиксированных форм поведения», Ю.В. Клочко «Ригидность В структуре готовности человека к изменению образа жизни» и О.В. Лукьянова «Проблема идентичности и психическая ригидность в психологической и образовательной практике», мы разработали программу тренинга направленного на формирование позитивного самоотношения студентов-психологов посредством тренинга развития флексибильности:

Цель программы: коррекция программы поведения в целом или отдельных ее элементов в соответствии с требованиями изменяющейся ситуации.

Достижение цели возможно в процессе реализации следующих задач: 1. Дать возможность самораскрытия и открытия необходимости изменения самого себя - самооценки, уровня притязаний, привычек; 2. Сформировать способность при объективной необходимости изменять мнение, отношение, установку, модус переживания; 3. Развить умение не испытывать трудности в ситуациях, требующих каких-либо перемен, нового подхода, решения. 4. Корректировать склонность к широкому спектру фиксированных форм поведения. 5. Обучить навыкам более эффективного взаимодействия с окружающими;

Данная программа рассчитана на 12 занятий. Частота встреч 2 раза в неделю во второй половине дня. Приблизительная продолжительность каждого занятия 1,5 часа.

Анализируя результаты первичной и повторной диагностик экспериментальной группы по методике «Опросник самоотношения», мы имеем возможность констатировать следующее: наиболее значимые изменения по шкале «Закрытость» зафиксированы средних и высоких значениях по шкале, по шкале «Самоуверенность» наблюдаются значимые изменения высоких и низких значениях по шкале, шкала «Саморуководство» изменения произошли высоких и низких значениях. Средние значения раскрывают особенности отношения к своему «Я» в зависимости от степени адаптированности в ситуации. В привычных для себя условиях существования, в которых все возможные изменения знакомы и хорошо прогнозируемы, человек может проявлять выраженную способность к личному контролю. По Шкале «Отраженное самоотношение» наблюдаются изменения в высоких и средних значениях. Низкие значения указывают на то, что человек относится к себе как к неспособному вызвать уважение у окружающих, как к вызывающему у других людей осуждение и порицание, по шкале «Самоценность» наблюдаются изменения в высоких и низких значениях. Средние значения отражают избирательное отношение к себе. Человек склонен высоко оценивать ряд своих качеств, признавать их уникальность. По Шкале «Самопринятие» изменения в высоких и низких значениях. Средние значения отражают избирательность отношения к себе, по шкале «Самопривязанность» изменения зафиксированы в высоких и средних и низких значениях шкалы. По Шкале «Внутренняя конфликтность» зафиксированы изменения в высоких и средних значениях, по шкале «Самообвинение» наблюдаются изменения в высоких и средних значениях по шкале. Низкие значения обнаруживают тенденцию к отрицанию собственной вины в конфликтных ситуациях. Защита собственного «Я» осуществляется путем обвинения преимущественно других, перенесением ответственности на окружающих за устранение барьеров на пути к достижению цели.

Повторная диагностика по методике ТОР выявила следующие показатели: У исследуемых студентов экспериментальной группы по шкале сенситивной ригидности (СР), которая отражает эмоциональную реакцию человека на новые ситуации, умеренный уровень составляет 57,14 \%, высокий уровень - 7,14 \% и низкий уровни $-35,74 \%$, очень высокий уровень по данной шкале не выявлен. Другими словами, более 90 \% исследуемых данной группы не испытывают страха перед новым, готовы к изменениям.

По шкале установочной ригидности (УР), которая отражает личностный уровень проявления ПР, выраженный в позиции, отношении или установке на принятиенепринятие нового, необходимости изменения самого себя - самооценки, уровня притязаний, системы ценностей 57,14 \% исследуемых экспериментальной группы имеют умеренную степень ПР, 28,58 \% - низкую степень проявления ПР, 14,26 \% - высокую степень ПР, очень высокий уровень ПР у студентов данной подгруппы не выявлено. Следовательно, более 80 \% исследуемых данной подгруппы готовы к принятию нового, к изменению себя - самооценки, уровня притязаний, системы ценностей и т.п. 
Ригидность как состояние (РСО) отражает, что в состоянии страха, стрессе, плохого настроения, утомления или болезни человек в высокой степени склонен к ригидному поведению, которое он может и не проявлять в обычных условиях. По данной шкале 64,28 \% исследуемых студентов экспериментальной группы имеют умеренную степень ПР. Тогда как, высокий уровень проявления ПР по данной шкале выявлен у 7,14 \%, а низкий уровень у $28,58 \%$. Эти данные могут свидетельствовать о том, что более 80 \% исследуемых данной подгруппы в состоянии стресса, утомления не склонны к ригидному поведению.

Симптомокомплекс ригидности (СКР) отражающий склонность к широкому спектру фиксированных форм поведения выявлен в следующем соотношении показателей: не выявлен очень высокий уровень проявления ПР. Низкая степень ПР характерна для 35,66\% исследуемых студентов экспериментальной группы, 42,88 \% исследуемых имеют умеренную степень ПР, следовательно для 21,46 \% респондентов характерна высокая степень проявления ПР. Следовательно, более 70\% склонны отходить от сложившихся стереотипов, фиксированных форм поведения.

Актуальная ригидность (АР), отражает неспособность при объективной необходимости изменить мнение, отношение, установку, мотивы, модус переживания выявлена в следующем соотношении: у 57,14 \% исследуемых экспериментальной группы наблюдается умеренная степень ПР, низкую степень ПР имеют 28,6 \% исследуемых, высокая степень выявлена у 14,26 \% исследуемых и очень высокая степень ПР по данной шкале не выявлены. Таким образом, для $80 \%$ исследуемых представителей данной подгруппы не составляет трудности изменить мнение при объективной необходимости, мотивы и т.п.

Преморбидная ригидность (ПР) отражает то, что исследуемый уже испытывал трудности в ситуациях, требующих каких-либо перемен, нового подхода, решения. По шкале ПМР у 42,88 \% исследуемых студентов экспериментальной группы выявлена умеренная степень ПР, у 35,74 \% исследуемых - низкая степень ПР, у 21,38 \% исследуемых - высокая степень ПР, исследуемые с очень высокой степенью ПР по данной шкале не выявлены.

Для определения эффективности проведения тренинга, мы использовали t-критерий Стьюдента (для связанных выборок). Анализ результатов статистической обработки данных по методике «Опросник самоотношения» В.В. Столина, С. Р. Пантилеева мы имеем возможность отметить следующее: полученное значение tэмп.=2,5 по шкале «Закрытость» находится в зоне значимости (t кр.=1,97; p < 0,05), что свидетельствует о статистической существенности различий между пока- зателями первичной и повторной диагностик; по шкале «Самоуверенность» значение так же находится в зоне значимости tэмп. $=2,6$ (t кр.=1,97; p < 0,05), что так же свидетельствует о статистической существенности различий между показателями первичной и повторной диагностик; полученное значение тэмп. $=2,3$ по шкале «Саморуководсво» находится в зоне значимости ( $\mathrm{t}$ кр. $=1,97$; $\mathrm{p}<0,05)$, что свидетельствует о статистической существенности различий между показателями первичной и повторной диагностик. Полученное значение тэмп. $=2,2$ по шкале «Отраженное самоотношение» находится в зоне значимости ( $\mathrm{kp} .=1,97 ; \mathrm{p}<0,05$ ), что свидетельствует о статистической существенности различий между показателями первичной и повторной диагностик; по шкале «Самоценность» значение так же находится в зоне значимости tэмп. $=2,6$ (t кр. $=1,97 ; p<0,05)$, значение tэмп.=2,5 по шкале «Самопринятие» находится в зоне значимости ( $\mathrm{kp} .=1,97 ; \mathrm{p}<0,05$ ), что свидетельствует о статистической существенности различий между показателями первичной и повторной диагностик. Полученное значение tэмп.=2,4 по шкале «Самопривязанность» находится в зоне значимости (t кр.=1,97; p < 0,05), по шкале «Внутренняя конфликтность» значение так же находится в зоне значимости tэмп. $=2,5$ (t кр.=1,97; p < 0,05), полученное значение tэмп.=2,3 по шкале «Самообвинение» находится в зоне значимости (t кр. $=1,97 ; p<0,05)$, что свидетельствует о статистической существенности различий между показателями первичной и повторной диагностик; полученное значение тэмп. $=2,4$ по шкале «Феминность-мускулинность» находится в зоне значимости (t кр.=1,97; $\mathrm{p}<0,05)$, что свидетельствует о статистической существенности различий между показателями первичной и повторной диагностик.

Анализ результатов статистической обработки данных по методике Томский опросник ригидности (ТОР) Г.В. Залевского мы имеем возможность отметить следующее: полученное значение tэмп. $=2,2$ по шкале «СР» находится в зоне значимости ( $\mathrm{kp} .=1,97$; $p<0,05)$, что свидетельствует о статистической существенности различий между показателями первичной и повторной диагностик; по шкале «УР» значение так же находится в зоне значимости tэмп. $=2,4$ (t кр.=1,97; $p<0,05$ ), что так же свидетельствует о статистической существенности различий между показателями первичной и повторной диагностик; полученное значение tэмп. $=2,5$ по шкале «РСО» находится в зоне значимости (t кр. $=1,97 ; p<0,05)$, что свидетельствует о статистической существенности различий между показателями первичной и повторной диагностик. Полученное значение тэмп. $=2,2$ по шкале «СКР» находится в зоне значимости (t кр.=1,97; $<<0,05)$, что свидетельствует о статистической существенности различий между показателями первичной и повторной диагностик; по шкале «АР» значение так же находится в зоне значимости тэмп. $=2,6$ (t кр. $=1,97 ; p<0,05)$, значение tэмп. $=2,5$ по шкале «ПР» находится в зоне значимости $(\mathrm{t}$ 
кр.=1,97; $<<0,05)$, что свидетельствует о статистической существенности различий между показателями первичной и повторной диагностик.

На основании данных статистической обработки, можно сделать вывод о том, что сравниваемые значения первичной и повторной диагностик статистически достоверно различаются с вероятностью допустимой ошибки меньше 0,05 у исследуемых экспериментальной группы по всем шкалам методики ТОР и «Опросник самоотношения». При этом статистических различий между результатами первичной и повторной диагностик в контрольной группе не выявлено.

Данные статистической обработки результатов исследования свидетельствуют о том, что реализуемая программа тренинга, направленного на формирование позитивного самоотношения студентов-психологов эффективна.

Таки образом, психологии представлено огромное количество исследований, в которых установлена тесная связь между отношением личности к себе как к субъекту жизненных отношений и ее поведением. Отмечается, что высокое самоуважение личности выступает условием ее максимальной активности, продуктивности в деятельности, реализации творческого потенциала, влияет на свободу выражения чувства, уровень самораскрытия в общении. Позитивное устойчивое самоот- ношение лежит в основании веры человека в свои возможности, самостоятельность, энергичность, связано с его готовностью к риску, обуславливает оптимизм в отношении ожидания успешности своих действий в ситуации неопределенности.

Негативное самоотношение является источником различных трудностей в общении, поскольку человек с таким отношением к себе заранее уверен в том, что окружающие плохо к нему относятся. Проблема достоинства, ценности своего «Я» почти полностью поглощает его внимание, в связи с чем уровень активности человека излишне повышается, затрудняя тем самым выбор адекватного способа взаимодействия, его поведение становится ригидным. Отрицательное, конфликтное отношение личности к себе обуславливает множество проблем, которые человек зачастую не в силах разрешить самостоятельно. Отношение личности к себе оказывает влияние на проявление социальной активности личности, обуславливает ее адекватность и дифференцированность. Оно выступает мотивом саморегуляции поведения и актуализируется на всех этапах осуществления поведенческого акта, начиная с его мотивирующих компонентов и заканчивая собственной оценкой достигнутого эффекта поведения, участвует в механизмах регуляции поведения от уровня конкретной ситуации деятельности до уровня длительной реализации идейных замыслов.

\section{ЛИТЕРАТУРА}

1. Галажинский, Э.В. Психическая ригидность как фактор дезадаптации учащихся младших классов: Дисс. канд. психол. наук. / Э.В. Галажинский. - Томск, 1996. -323 c.

2. Залевский, Г.В. Психическая ригидность в норме и патологии: Учеб. для вузов / Г.В. Залевский. - Томск: Изд-во Том. унив.- 1993.- 272 с.

3. Клочко, Ю.В. Ригидность в структуре готовности человека к изменению образа жизни: автореф. дис. канд. психол. наук / Ю.В. Клочко. - Барнаул, 2002.

4. Клочко, В.Е. Человек как психологическая система // Сибирский психологический журнал. -1994. - № 7. - С.38 - 196 с.

5. Колкова, С.М. Безусловное самопринятие как фактор развития гуманистических качеств личности будущих психологов. диссертация... кандидата психологических наук : 19.00.13 / С.М. Колкова. - Красноярск, 2006.

6. Логинова, И.О. Жизненное самоосуществление: системно-антропологический контекст: автореф. дис. д-ра психол. наук. Спец.: 19.00.01-общая психология, история психологии, психология личности / И.О. Логинова.- Томск, 2010.

7. Лукьянов, О.В. Проблема идентичности и психической ригидности в психологической образовательной практике: Диссертац. исслед. / 0.В. Лукъянов. Томск, 1999.

8. Пантилеев С.Р. Методика исследования самоотношения. - М.: «СМЫСЛ», 1993. - 32 с.

9. Сарджвеладзе, Н.И. Структура самоотношения личности и социогенные потребности / В кн.: Проблемы формирования социогенных потребностей. Тбилиси, Мецниереба, 1974. - С. 103-107.

10. Столин, В.В., Пантилеев С.Р. Опросник самоотношения / В кн.: Практикум по психодиагностике. Психодиагностические материалы. Под ред. Бодалева А.А., Карлинской И.М., Столина В.В., Пантилеева С.Р. - М., 1988. - С. 123-130. 